\title{
Aplikasi Response Surface Methodology (RSM) Untuk Mempersingkat Waktu Pengeringan Sheet di Pabrik Pengolahan Sheet PTPN III Kebun Sarang Giting
}

\author{
Erinsyah Maulia Rangkuti ${ }^{1}$, A. Rahim Matondang ${ }^{2}$, Nazaruddin ${ }^{3}$ \\ Departemen Teknik Industri, Fakultas Teknik, Universitas Sumatera Utara \\ Jl. Almamater Kampus USU, Medan 20155 \\ Email: erinsyahmaulia@gmail.com
}

\begin{abstract}
Abstrak. Karet adalah kebutuhan vital bagi kehidupan manusia, terkait dengan mobilitas manusia dan barang yang terbuat dari karet. Kebutuhan karet alam maupun sintetik terus meningkat sejalan dengan meningkatnya standar hidup manusia. Karet jenis RSS (Ribbed Smoke Sheet) merupakan produk unggulan PT Perkebunan Nusantara III. Proses pengolahan lateks menjadi sheet melalui 4 stasiun kerja yaitu : penggumpalan, penggilingan, pengeringan dan sortasi. Tiap stasiun kerja memiliki kapasitas tertentu. Kapasitas stasiun pengeringan 12.000 Kg/hari merupakan kapasitas terkecil yang menjadi dasar penentuan kapasitas. Sedangkan bahan baku yang diterima berkisar antara 12.000-14.000 Kg/hari. Oleh karena itu pada saat kapasitas kamar asap maksimal, banyak bahan setengah jadi yang harus menunggu proses pengeringan. Peristiwa ini dikhawatirkan akan menyebabkan rusaknya mutu produk. Kapasitas kamar asap dipengaruhi oleh waktu pengeringan. Waktu pengeringan saat ini mencapai 120 jam persiklus. Untuk mendapatkan kapasitas yang lebih besar dapat dilakukan dengan mempersingkat siklus produk salah satunya dengan mempersingkat waktu pengeringan. Berdasarkan uraian diatas permasalahan yang dibahas adalah bagaimana mempersingkat waktu pengeringan sheet dikamar asap, sehingga kapasitas olah pabrik dapat meningkat. Faktor-faktor pada proses pengolahan sheet yang berpengaruh terhadap pencapaian hasil antara lain jumlah bahan kimia, waktu tunggu, dan persentase DRC pengenceran. Faktor yang merespon perlakuan adalah produk reject. Mengoptimalkan interaksi antar faktor pengolahan dengan mengaplikasikan respon surface methodology (RSM). Dari hasil rancangan proses pengolahan sheet diperoleh kapasitas olah meningkat dari maksimal $12.000 \mathrm{Kg}$ kering perhari menjadi $13.458 \mathrm{Kg}$ kering perhari. Perlakuan tersebut dilakukan dengan memperkecil ukuran ketabalan lembaran menjadi 3,1 mm namun meningkatkan persentase produk reject dari 0,2\% menjadi $0,43 \%$.
\end{abstract}

Kata Kunci: Ribbed Smoke Sheet, kapasitas pabrik, Response Surface Methodology (RSM)

\begin{abstract}
Rubber is vitallity needed for our activities which are related to human and goods mobility that need components made of rubber. The need for rubber or synthetic is increasing, along with the increase in human life. RSS (Ribbed Smoke Sheet) rubber type is the high rangking product of PT Perkebunan Nusantara III. The processing of latex to sheet is through four work stations: gathering, milling, drying, and sorting. Each of work station has certainly mill capacity. Drying capacity of $12.000 \mathrm{Kg} /$ day is the smallest capacity which becomes the basis for determining the capacity, while raw material received is between 12.000 and 13,000 Kg/day. Therefore, when the capacity of smoke room has been maximal, a lot of half-finished materials have to wait for drying process. This condition migh make the product quality bad. The capacity of smoke room is influenced by drying time. The drying time now is 120 hours per cycle. To get more capacity can be done by shortening drying time. The research problem is how to shorten sheet drying time in smoke room so that the mill capacity can increase. Some factors which influence production achievement are the measurement of chemical materials, waiting time, and percentage of retailing DRC (Dryied Rubber Contain). The factor which responds to treatment is the percentage of reject product by optimizing interaction between processing and implementation of RSM. The outcome of sheet processing that processing capacity increases from maximally $12.000 \mathrm{~kg} /$ day dry to $13.458 \mathrm{~kg} /$ day dry. This treatment is done by lessening the thickness to 3,1 mm, but increase the percentage of reject product form 0,2 to 0,43.
\end{abstract}

Keywords: Ribbed Smoke Sheet, Mill Capacity, Response Surface Methodology (RSM)

\footnotetext{
${ }^{1}$ Mahasiswa Sekolah Pascasarjana Departemen Teknik Industri Fakultas Teknik Universitas Sumatera Utara

2 Dosen Departemen Teknik Industri Fakultas Teknik Universitas Sumatera Utara

${ }^{3}$ Dosen Departemen Teknik Industri Fakultas Teknik Universitas Sumatera Utara
} 


\section{PENDAHULUAN}

Karet adalah kebutuhan yang vital bagi kehidupan manusia sehari - hari, hal ini terkait dengan mobilitas manusia dan barang yang memerlukan komponen yang terbuat dari karet. Kebutuhan karet alam maupun sintetik terus meningkat sejalan dengan meningkatnya standar hidup manusia. Kebutuhan karet sintetik relatif lebih mudah dipenuhi karena sumber bahan baku relatif tersedia walaupun harganya mahal, akan tetapi karet alam tetap menjadi pilihan sebagai bahan baku industri yang berbahan baku karet. Karet jenis RSS (Ribbed Smoke Sheet) merupakan produk unggulan yang alami dari PT Perkebunan Nusantara III. Produk karet alam sangat baik digunakan sebagai bahan baku terutama untuk bermacam-macam industri karet, sehingga permintaan jenis RSS ini semakin meningkat dari tahun ke tahun (Palupi N.P, 2008).

Proses pengeringan RSS (ketebalan lembaran \pm 4 mm) membutuhkan waktu selama 5 hari (Purba L.P, 2008). Kondisi ini membatasi daya tampung kamar asap. Artinya semakin cepat sheet matang maka kapasitas olah pabrik akan semakin besar. Sebaliknya, jika sheet matang dalam waktu lebih dari 5 hari maka daya tampung kamar asap akan berkurang sehingga terjadi stagnasi (bottleneck) dimana produksi yang masuk tidak bisa langsung di keringkan dan harus menunggu di luar kamar asap. Menurut Muis Y (2007) Kondisi ini dikhawatirkan akan menyebabkan rusaknya mutu sheet seperti timbulnya cendawan (jamur) pada sheet, bercak karat pada sheet, dan timbulnya gelembung-gelembung udara pada sheet. Oleh karena itu agar tidak terjadi bottleneck waktu pengeringan sheet harus direkayasa agar menjadi lebih singkat..

\section{METODE PENELITIAN}

Penentuan variabel penelitian didasarkan atas studi pendahuluan, studi kepustakaan, dan pengalaman pihak perusahaan yang berkaitan dengan permasalahan yang sedang dihadapi.

\subsection{Variabel Penelitian}

Adapun variabel yang terdapat dalam penelitian ini adalah sebagai berikut:

1. Variabel Dependen.

Variabel dependen dalam penelitian ini adalah Waktu Pengeringan

2. Variabel Independen.

Variabel independen dalam penelitian ini adalah Persentase DRC pengenceran, waktu tunggu, dan jumlah bahan kimia

Suatu penelitian dapat dilaksanakan apabila tersedianya sebuah perancangan kerangka berpikir yang baik sehingga langkah-langkah penelitian lebih sistematis. Kerangka berpikir inilah yang merupakan landasan awal dalam melaksanakan penelitian. Adapun kerangka berpikir penelitian ini dapat dilihat pada Gambar 1.

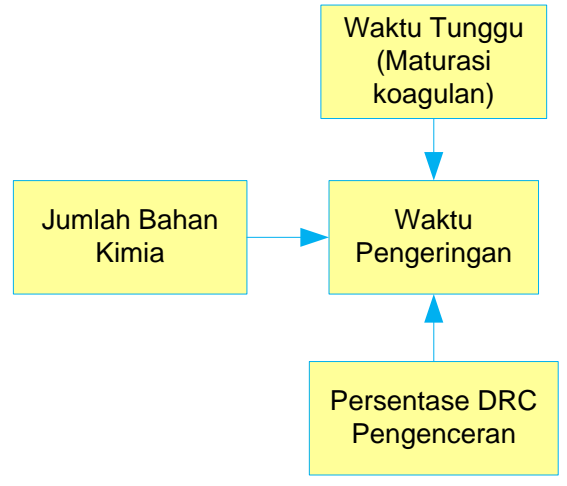

Gambar 1. Kerangka Konseptual Penelitian

\subsection{Metode Pengumpulan Data}

Pada pengumpulan data untuk penelitian ini berasal dari data primer dan data sekunder yaitu :

1. Data primer yang dibutuhkan dalam penelitian ini adalah data yang diperoleh melalui observasi terhadap perancangan eksperimen yang dilakukan di bagian produksi karet sheet dimana data yang dikumpulkan adalah pada masing-masing interaksi perlakuan taraf faktor dari faktor apa saja yang mempengaruhi proses produksi karet sheet.

2. Data sekunder dalam penelitian ini antara lain : data tentang norma-norma pengolahan sheet seperti norma busa maksimal yang diperbolehkan, norma pengenceran lateks, norma bahan kimia, norma ketebalan lembaran, norma waktu dan suhu di kamar asap.

\subsection{Metode Pengolahan Data}

Pengolahan data dalam penelitian ini mengikuti prosedur sebagai berikut (Chang K.H, 2013):

1. Penentuan titik setting faktor Response surface Methodology

2. Pengumpulan data model orde pertama

3. Pengolahan data model orde pertama

4. Penentuan model orde kedua

5. Penentuan titik optimum faktor

\section{HASIL DAN PEMBAHASAN}

\subsection{Titik Setting faktor}

Titik setting faktor perlu ditetapkan karena dalam penelitian ini menggunakan rancangan $2 \mathrm{k}$ yang menghendaki adanya level rendah dan level tinggi dari faktor yang diteliti (Anggun M.E, 2004). Level tinggi dari masing-masing faktor akan disimbolkan dengan angka 1, sedangkan level rendah dari masing-masing faktor akan disimbolkan dengan angka -1. Penetapan titik setting dapat dilihat pada Tabel 1. 
Tabel 1. Titik Setting Faktor

\begin{tabular}{cccc}
\hline Faktor & -1 & 0 & 1 \\
\hline Jumlah bahan kimia (Kg/ton) & 7,5 & 8 & 8,5 \\
Waktu tunggu (jam) & 2 & 4 & 6 \\
Persentase DRC pengenceran & 13 & 14 & 15 \\
\hline
\end{tabular}

Dari Tabe.1 dapat dilihat bahwa titik setting faktor penelitian awal adalah titik faktor 0 sedangkan titik -1 adalah titik minimu faktor penelitian dan 1 titik maksimum faktor penelitian.

\subsection{Pengumpulan dan Pengolahan Model Orde Pertama}

Setelah penetapan faktor, maka langkah selanjutnya adalah melakukan pengumpulan data. Perlakuan yang dilakukan ada sebanyak 9 perlakuan, 8 perlakuan berasal dari perlakuan desain $2 \mathrm{k}$ dan 1 perlakuan pada titik pusat yang didasarkan pada jumlah blok titik kubus pada Tabel 2.

Tabel 2. Data Model Orde Pertama

\begin{tabular}{cccccc}
\hline Perlakuan & $\mathrm{X} 0$ & $\mathrm{X} 1$ & $\mathrm{X} 2$ & $\mathrm{X} 3$ & $\begin{array}{c}\mathrm{Y} \\
(\%)\end{array}$ \\
\hline 1 & 1 & -1 & -1 & -1 & 1,56 \\
2 & 1 & 1 & -1 & -1 & 1,49 \\
3 & 1 & -1 & 1 & -1 & 0,78 \\
4 & 1 & 1 & 1 & -1 & 0,69 \\
5 & 1 & -1 & -1 & 1 & 1,15 \\
6 & 1 & 1 & -1 & 1 & 1,07 \\
7 & 1 & -1 & 1 & 1 & 0,89 \\
8 & 1 & 1 & 1 & 1 & 0,95 \\
9 & 1 & 0 & 0 & 0 & 0,80 \\
\hline
\end{tabular}

Dari data pada Tabel.2. model orde pertama ditentukan. Hasilnya berupa persamaan orde pertama yaitu $\mathrm{Y}=1,042-0,023 \mathrm{X} 1-0,245 \mathrm{X} 2-0,058 \mathrm{X} 3$.

Dari hasil persamaan orde pertama dilakukan kembali pengumpulan data untuk melakukan steepest descent seperti pada Tabel 3.

Tabel 3. Perhitungan Pergerakan Level Steepest Descent

\begin{tabular}{lccc}
\hline \multicolumn{1}{c}{ Prosedur } & $\mathrm{X} 1$ & $\mathrm{X} 2$ & $\mathrm{X} 3$ \\
\hline $\begin{array}{l}\text { Perubahan relatif } \\
\text { pada unit desain } \\
\text { (bi) }\end{array}$ & & - & \\
$\begin{array}{l}\text { Unit origin (1 } \\
\text { unit desain) }\end{array}$ & -0.023 & 0.245 & -0.058 \\
$\begin{array}{l}\text { Perubahan relatif } \\
\text { pada unit origin }\end{array}$ & 0.01125 & -0.49 & -0.0575 \\
$\begin{array}{l}\text { Perubahan per n } \\
\text { pada variabel i }\end{array}$ & & & \\
$(\Delta)$ & 0.02 & 1.00 & 0.12 \\
\hline
\end{tabular}

\begin{tabular}{lcccc}
\hline \multicolumn{1}{c}{$\begin{array}{c}\text { Pergerakan } \\
\text { Steepest Descent }\end{array}$} & $\mathrm{X} 1$ & $\mathrm{X} 2$ & $\mathrm{X} 3$ & $\begin{array}{c}\text { Hasil } \\
\text { percobaan } \\
(\%)\end{array}$ \\
\hline $\begin{array}{l}\text { Level awal } \\
(\text { origin }=0)\end{array}$ & 8 & 4 & 14 & - \\
$\begin{array}{l}\text { Pergerakan Level } \\
(\mathrm{o}+\mathrm{n} \Delta) ; \mathrm{n}=1\end{array}$ & 8.02 & 5.00 & 14.12 & 0.71 \\
$\begin{array}{l}\text { Pergerakan Level } \\
(\mathrm{o}+\mathrm{n} \Delta) ; \mathrm{n}=2\end{array}$ & 8.05 & 6.00 & 14.23 & 0.61 \\
$\begin{array}{l}\text { Pergerakan Level } \\
(\mathrm{o}+\mathrm{n} \Delta) ; \mathrm{n}=3\end{array}$ & 8.07 & 7.00 & 14.35 & 0.52 \\
$\begin{array}{l}\text { Pergerakan Level } \\
(\mathrm{o}+\mathrm{n} \Delta) ; \mathrm{n}=4\end{array}$ & 8.09 & 8.00 & 14.47 & 0.43 \\
$\begin{array}{l}\text { Pergerakan Level } \\
(\mathrm{o}+\mathrm{n} \Delta) ; \mathrm{n}=5\end{array}$ & 8.11 & 9.00 & 14.59 & 0.63 \\
$\begin{array}{l}\text { Pergerakan Level } \\
(\mathrm{o}+\mathrm{n} \Delta) ; \mathrm{n}=6\end{array}$ & 8.14 & 10.00 & 14.70 & 0.75 \\
\hline
\end{tabular}

Berdasarkan Tabel.3 Penentuan titik origin adalah berdasarkan kepada pergerakan level yang memberikan jumlah cacat yang paling minimum yaitu pada pergerakan level pada $\mathrm{n}=4$, dimana $\mathrm{x}_{1}=8,09 \mathrm{~kg} / \mathrm{ton} ; \mathrm{x}_{2}$ $=8 \mathrm{jam} ; \mathrm{x}_{3}=14.47 \%$ dengan persentase produk Reject $0,43 \%$.

\subsection{Penentuan Model Orde Kedua}

Menurut Benttocil (2009) Model orde kedua diperoleh dengan metode central composite design. Nilai faktor yang telah diketahui pada langkah diatas akan digunakan pada percobaan ini, dimana terlebih dahulu ditentukan level tertinggi dan level terendah dari masingmasing faktor dengan acuan terhadap unit origin pada Tabel 4.

Tabel 4. Nilai Faktor setelah Steepest Descent

\begin{tabular}{lccc}
\hline \multicolumn{1}{c}{ Faktor } & -1 & 0 & 1 \\
\hline Jumlah bahan kimia $\left(x_{1}\right)$ & 7,59 & 8,09 & 8,59 \\
Waktu tunggu $\left(x_{2}\right)$ & 6 & 8 & 10 \\
Persentase DRC & 13,47 & 14,47 & 15,47 \\
pengenceran $\left(x_{3}\right)$ & & & \\
\hline
\end{tabular}

Berdasarkan Tabel.4 nilai faktor steepest descent Didalam Central Composite Design (CCD) terdapat star points $(\alpha)$ ditentukan oleh rumus: $\alpha=2 \mathrm{k} / 4$. Dalam hal ini nilai $\alpha$ adalah $23 / 4= \pm 1,68$. Nilai $\alpha$ untuk masingmasing faktor dapat dilihat pada Tabel 5 .

Tabel 5. Nilai $\alpha$ untuk Masing - masing Faktor

\begin{tabular}{cccc}
$\alpha$ & $x_{1}$ & $x_{2}$ & $x_{3}$ \\
\hline 1.68 & 8.93 & 11.36 & 16.15 \\
-1.68 & 7.25 & 4.64 & 12.79 \\
\hline
\end{tabular}

Dari Tabel.5 nilai dari faktor diketahui maka akan dilakukan pengumpulan data untuk pembuatan model orde kedua. Berikut ini adalah data-data yang 
dikumpulkan untuk menunjang penelitian yang dilakukan yaitu: data persentase produk Reject pada Central Composite Design. Data berikut ini adalah data yang dikumpulkan selama 15 hari yang ditunjukan pada Tabel 6.

\begin{tabular}{|c|c|c|c|c|c|c|c|c|c|c|c|}
\hline Perlakuan & $x_{0}$ & $x_{2}$ & $x_{2}$ & $x_{3}$ & $\mathrm{X}_{2}{ }^{2}$ & $\mathrm{X}_{2}{ }^{2}$ & $\mathrm{Xg}^{2}$ & $x_{1} x_{2}$ & $x_{2} x_{9}$ & $x_{2} x_{0}$ & $Y(\%)$ \\
\hline 1 & 1 & -1 & -1 & -1 & 1 & 1 & 1 & 1 & 1 & 1 & 0.46 \\
\hline 2 & 1 & 1 & -1 & -1 & 1 & 1 & 1 & -1 & -1 & 1 & 0.40 \\
\hline 3 & 1 & -1 & 1 & -1 & 1 & 1 & 1 & -1 & 1 & -1 & 0.37 \\
\hline 4 & 1 & 1 & 1 & -1 & 1 & 1 & 1 & 1 & -1 & -1 & 0.47 \\
\hline 5 & 1 & -1 & -1 & 1 & 1 & 1 & 1 & 1 & -1 & -1 & 0.32 \\
\hline 6 & 1 & 1 & -1 & 1 & 1 & 1 & 1 & -1 & 1 & -1 & 0.48 \\
\hline 7 & 1 & -1 & 1 & 1 & 1 & 1 & 1 & -1 & -1 & 1 & 0.32 \\
\hline 8 & 1 & 1 & 1 & 1 & 1 & 1 & 1 & 1 & 1 & 1 & 0.48 \\
\hline 9 & 1 & 1.68 & 0 & 0 & 2.822 & 0 & 0 & 0 & 0 & 0 & 0.33 \\
\hline 10 & 1 & 1.68 & 0 & 0 & 2.822 & 0 & 0 & 0 & 0 & 0 & 0.39 \\
\hline 11 & 1 & 0 & 1.68 & 0 & 0 & 2.822 & 0 & 0 & 0 & 0 & 0.42 \\
\hline 12 & 1 & 0 & 1.68 & 0 & 0 & 2.822 & 0 & 0 & 0 & 0 & 0.38 \\
\hline 13 & 1 & 0 & 0 & 1.68 & 0 & 0 & 2.822 & 0 & 0 & 0 & 0.30 \\
\hline 14 & 1 & 0 & 0 & 1.68 & 0 & 0 & 2.822 & 0 & 0 & 0 & 0.43 \\
\hline 15 & 1 & 0 & 0 & 0 & 0 & 0 & 0 & 0 & 0 & 0 & 0.39 \\
\hline
\end{tabular}

Dari data perhitungan orde kedua pada Tabel.6 maka telah dapat diperoleh persamaan model orde kedua yaitu:

$\mathrm{Y}=0.395+0.034 \mathrm{x}_{1}-0.006 \mathrm{x}_{2}+0.007 \mathrm{x}_{3}+0.222 \mathrm{x}_{12}+$ $0.232 \mathrm{x}_{22}+0.223 \mathrm{x}_{32}+0.019 \mathrm{x}_{1} \mathrm{x}_{2}+0.037 \mathrm{x}_{1} \mathrm{x}_{3}+0.004$ $\mathrm{x}_{2} \mathrm{X}_{3}$

\subsection{Penentuan Titik Optimum Faktor}

Dari persamaan orde kedua maka koefisien masingmasing variabel diubah ke dalam bentuk matriks. Pembentukan matriks dan penentuan titik optimum dicari dengan cara perkalian dan invers matriks yang prinsip pengerjaannya telah dijelaskan pada perhitungan sebelumnya (Myers, R.H, 2009). Hasil perhitungan dapat dilihat dibawah:

$$
\left|\begin{array}{l}
\mathrm{x}_{1} \\
\mathrm{x}_{2} \\
\mathrm{x}_{3}
\end{array}\right|=\left|\begin{array}{c}
-0.076 \\
0.016 \\
-0.009
\end{array}\right|
$$

Penentuan nilai optimum secara teoritis adalah sebagai berikut:

Nilai optimum untuk jumlah bahan kimia

$\xi \mathrm{i}=\mathrm{Xi}\left(\Delta \mathrm{x}_{(-1,+1)} / 2\right)+$ Xorigin

$\xi 1=-0,076((8,59-7,59) / 2)+8,09=8,052$

Nilai optimum untuk waktu tunggu

$\xi 1=0,016((10-6) / 2)+8=8,032$

Nilai optimum untuk persentase DRC pengenceran $\xi 1=-0,009((15,47-13,47) / 2)+14,47=14,461$

\subsection{Kondisi existing vs Rancangan.}

Kondisi existing adalah adalah kondisi dimana faktor penelitian belum berubah. Nilai faktor penelitian mengikuti kondisi yang berlaku di pabrik. Faktor-faktor penelitian dan nilainya tersebut dapat dilihat pada Tabel 7.
Tabel 7. Kondisi Existing dan Rancangan

\begin{tabular}{cccc}
\hline Kondisi & Existing & Rancangan & Selisih \\
\hline Jumlah bahan & 8 & 8.052 & 0.052 \\
$\begin{array}{c}\text { Kimia (Kg/ton) } \\
\text { Waktu Tunggu } \\
\text { (jam) }\end{array}$ & 4 & 8.032 & 4.032 \\
$\begin{array}{c}\text { Persentase DRC } \\
\text { Pengenceran (\%) }\end{array}$ & 14 & 14.461 & 0.461 \\
\hline
\end{tabular}

Dari Tabel 7. ketebalan lembaran pada kondisi existing 4 $\mathrm{mm}$ di perkecil menjadi $3,1 \mathrm{~mm}$. Penggunaan bahan kimia pada kondisi existing $8 \mathrm{~kg} / \mathrm{ton}$ karet kering, menjadi $8,052 \mathrm{~kg} /$ ton karet kering. Peningkatan penggunaan bahan kimia tidak terlalu besar sehingga masih dapat dikatakan sama. Waktu tunggu meningkat dari 4 jam menjadi 8 jam, hal ini bertujuan agar kondisi sheet yang akan digiling lebih kokoh, kekar dan tidak mudah rusak. Persentase DRC pengenceran juga harus dinaikkan dari $14 \%$ menjadi 14,46 atau $\approx 14,5 \%$.

3.6. Perbandingan Hasil

Hasil rancangan yang diharapkan adalah meningkatnya kapasitas olah pabrik. Kapasitas pabrik meningkat jika waktu pengeringan dapat dipersingkat. Berikut pada Tabel 8. dapat dilihat hasil perbandingan exsisting vs rancangan .

Tabel 8. Perbandingan Hasil

\begin{tabular}{cccc}
\hline Faktor Analisis & Existing & Rancangan & Selisih \\
\hline $\begin{array}{c}\text { Persentase Produk } \\
\text { Reject }(\%)\end{array}$ & 0.2 & 0.43 & 0.57 \\
$\begin{array}{c}\text { Ketebalan } \\
\text { Lembaran (mm) } \\
\quad \text { Waktu }\end{array}$ & 4 & 3,1 & $-0,9$ \\
$\begin{array}{c}\text { Pengeringan (jam) } \\
\text { Kapasitas } \\
\text { (ton/hari) }\end{array}$ & 120 & 107 & -13 \\
\hline
\end{tabular}

Rancangan ini dari awal dibuat untuk mendapatkan kapasitas olah yang lebih besar. Dari hasil rancangan yang didapat, kapasitas olah naik dari maksimal 12.000 $\mathrm{Kg}$ kering perhari menjadi $13.458 \mathrm{Kg}$ kering perhari seperti diperlihatkan dalam Tabel.8.

\section{KESIMPULAN} adalah:

Kesimpulan yang diperoleh dari hasil penelitian ini

1. Rancangan perbaikan yang diterapkan mempersingkat waktu pengeringan sheet dimana waktu pengeringan awal $\left(\mathrm{W}_{0}\right)=120$ jam menjadi waktu pengeringan rancangan $\left(\mathrm{W}_{1}\right)=107 \mathrm{jam}$.

2. Melalui rancangan perbaikan waktu pengeringan yang dilakukan kapasitas meningkat $12,15 \%$ dari $12.000 \mathrm{Kg}$ perhari menjadi $13.458 \mathrm{Kg}$ perhari. 


\section{DAFTAR PUSTAKA}

1. Anggun, M. E. (2004), Black Box simulation optimization : generalized response surface methodology. Centre Dissertation series, Tilburg University, Tilburg, the Netherlands.

2. Barnes, E. R. (1986). A variation on karmarkar's algoritm for solving linear programming problems. Mathematical programming, 36, pp 174-182

3. Bettoncil, B. W. M. E, del Castilo. And J. P. C Kleijnen (2009). Statistical testing of optimality conditions in multiresponse simulation-based optimization. European Journal of Operation Research, 199(2), 448-458.

4. Chang, K.H, J. Hong and H. Wan (2013) Stochastic Trust-region response surface method (STRONG). A new response surface framework for simulation optimization, informs journal on computing, 25 no. 2 pp 230-243

5. Faturakhman, J.A dan Ika Rasti Julia Sari. (2014). The correlation of using formic acid to ammonia concentration on rubber sheet product quality improvement. Badan pengkajian iklim dan mutu industry. Yogyakarta.

6. Kleijnen, J.P.C. den Hertog and E. Angun. (2004). Response surface methodology Steepest ascent and step size revidsited. European Journal of Operation Research, 159 pp 121-131

7. Kleijnen, J.P.C. den Hertog and E. Angun. (2006). Response surface methodology steepest ascent and step size revisited : correction, European Journal of Operational Research, 170 pp 664-666

8. Montgomery, Douglas C ad Geourge Runger. 2002. "applied statistic and probability for engineers. Third edition. John willey \& Son. Newyork

9. Muis, Y. 2007. Pengaruh Penggumpalan Asam Asetat, Asam Formiat, dan Berat Arang Tempurung Kelapa terhadap Mutu Lateks. Jurnal Sains Kimia. Vol 11, No. 1, 2007 : 21-24. Medan

10. Myers, R.H, D.C Montgomery and C.M. Andersoncook. (2009), response surface methodology : process and product optimization using designed experiment : Third edition. Wiley, Newyork

11. Palupi, N.P, Dkk. 2008. Karakterisasi perekat siklo karet alam. Jurnal teknologi pertanian. ISSN 18582419. Vol 4 No. 1. Universitas Mulawarman. Samarinda

12. Purba L.P, Tessakasul P. Maliwan K, dan Furuuchi M. CFD study of flow in a natural rubber smoking cooperative : turbulence free convection airflow. Proceeding of the 22nd mechanical engineering network of thailad. MENNET22, 15th -17th October 2008, Rangsit, Bangkok, Thailand. 